\title{
THE EFFECT OF CHLORPROMAZINE ON THE ELECTROENCEPHALOGRAM OF EPILEPTIC PATIENTS*
}

\author{
BY \\ WALTER FABISCH \\ From the Mapperley Hospital, Nottingham
}

Investigations by Courvoisier, Fournel, Ducrot, Kolsky, and Koetschet in 1953 had shown that chlorpromazine reduces convulsions in mice after coramine and in rabbits after nicotine Therefore, the drug seemed to suggest itself as an anticonvulsant in epilepsy But in 1954 Bente and Itil, De Castro and Bérard, and Mayr and Lechner observed activation of the electroencephalogram (E.E.G.) in epilepsy after the injection of chlorpromazine, and similar findings were reported in that year by Terzian and Ruberti. In 1954, 1955, and 1956 clinical observers noticed that some patients suffering from idiopathic epilepsy showed an increased number of seizures after chlorpromazine and there were also reports of more frequent epileptiform seizures after brain surgery, insulin coma treatment, in old age, and among large not otherwise specified groups of patients in mental hospitals during treatment with the drug (Barsa and Kline, 1956; Bonafede, 1955; Denber and Bird, 1955; Fabisch, 1955; Kinross-Wright, 1955; Lomas, Boardman, and Markowe, 1955; Munzinger, 1954; Robb, 1955; Samad, 1955; Schlichther, Bristow, Schultz, and Henderson, 1956; Schmid, 1954; Vaughan, Lieberman, and Cook, 1955). Activation of the E.E.G. in patients with idiopathic epilepsy and symptomatic epileptiform seizures was reported by some of these authors as well as by Lyberi and Last (1956), Szatmari (1956), Turner, Bérard, Turner, and Franco (1956), Zanocco (1955), Balestrieri (1955), and Balestrieri and Franceschini (1956) observed that in rabbits chlorpromazine in doses up to $10 \mathrm{mg}$. $/ \mathrm{kg}$. rarely raises but more often lowers the threshold for pharmacologically and electrically induced convulsions. However, Moyer, KinrossWright, and Finney (1955) reported that three out of four epileptic patients were improved with oral chlorpromazine. The fourth patient was made much worse. The present investigation and a survey of the literature was started when an epileptic patient, who

* Part of this paper was read at the international European meeting of the E.E.G. Society in London in May, 1956. had been free from convulsions for about two years and was given chlorpromazine against a tension state, suffered a convulsive seizure under photic stimulation during a routine E.E.G. examination.

\section{Material and Method}

The first group consisted of epileptic patients, whose electroencephalographic characteristics were known from earlier recordings. They were selected both from hospital wards and an out-patient clinic and were grouped as follows:- (a) Patients with persistently abnormal inter-seizure recordings (20 patients, 14 male, six female, ages 5 to 62 years, mean 30 years); (b) patients with fairly normal inter-seizure recordings (20 patients, 13 male, seven female, ages 16 to 58 years, mean 32 years).

The second group was a control group of patients from hospital wards and from out-patient clinics excluding any cases with seizures or head injuries, or who had been subjected to brain surgery, insulin coma treatment, electric convulsive treatment for at least four months, or to whom " tranquillizing" drugs had been administered. This group consisted of patients diagnosed as psychoneurotic, unstable personality and early schizophrenia in the younger age group, psychoneurosis and paraphrenia in the middle age group, and chronic schizophrenia and high grade mental defect in the older age group ( 20 patients, 15 male, five female, ages 18 to 65 years, mean 37.6 years). In most of these cases at least one E.E.G. had been taken previously.

One millilitre of a commercial chlorpromazine solution containing $25 \mathrm{mg}$. of the drug was diluted to $10 \mathrm{ml}$. with normal saline. Of this dilution $1 \mathrm{ml}$. was injected intravenously every 1 to $1 \frac{1}{2}$ minutes up to a maximum of 0.3 to $0.5 \mathrm{mg}$. per $\mathrm{kg}$. body weight. Immediately before the injection a routine E.E.G., including overbreathing and photic stimulation, was taken and the recording continued while the injection was given. The effect of the drug on the E.E.G. was observed as a rule for 40 to 45 minutes from the start of the injection. More than $25 \mathrm{mg}$. of chlorpromazine in all was not used in any case even if the weight exceeded $75 \mathrm{~kg}$. Usually the patients had been fasting for about six hours before the investigation.

Medication with anticonvulsants, and, in the control group, with sedatives remained unchanged except in two cases where physicians sending patients from outside 
the hospital had discontinued anticonvulsants during the week before the investigation.

Columns 1 to 4 of Table I summarize the distribution of sex, age, number of seizures, and some aspects of medication in the three groups. Epileptic patients in Group (a) have more seizures although they receive more of a greater variety of drugs than epileptic patients in Group (b). In the control group there are no seizures recorded, and sedation at night in the five cases shown consisted in sod. amylobarb. 100 to $200 \mathrm{mg}$., butobarbitone, $100 \mathrm{mg}$., and paraldehyde, $8 \mathrm{ml}$., respectively. Column $5 a, b$, and $c$, summarizes the number of cases showing three types of abnormal E.E.G. findings in the three groups, namely, delta activity, spikes, and spikeand-wave (" petit mal " pattern) in the resting recording, and after activation by overbreathing and stroboscopic flicker. The effects of activation by chlorpromazine are summarized in column $5 d$. Epileptic patients in Group (a) show a much higher incidence of the three abnormalities than those in Group (b) and the controls.

\section{Results}

Normal Controls.-About 15 minutes after the beginning of the injection of chlorpromazine when the patient appears to get drowsy the E.E.G. shows a general decrease in amplitude, most conspicuously in the posterior parts. The dominant frequency, i.e., usually the alpha, slows down by 1 to $2 \mathrm{c}$./sec. Theta activity of 5 to $7 \mathrm{c}$. $/ \mathrm{sec}$. becomes more prominent and spreads from the posterior parts to the intermastoid plane and sometimes further forward. At the same time muscle spike artefact usually decreases. Posterior sharp waves of about 250 to $300 \mathrm{~m} . \mathrm{sec}$. duration, resembling lambda waves, are often seen after about 20 to 30 minutes. Occasionally
2 to $3 \mathrm{c}$./sec. activity of moderately high amplitude develops in the posterior parts. Very often the E.E.G. becomes in general flat and featureless. Acoustic and tactile stimuli usually cause the return of higher amplitude activity after one to one and a half seconds. The same happens when the patient stirs spontaneously, i.e., again most probably in response to tactile stimuli or painful sensations, or if the light is turned on in the room. In cases where apparently the level of drowsiness is deeper tactile and acoustic stimuli may elicit responses resembling $\mathrm{K}$ complexes.

Epileptic Patients in Group (b).-These patients with fairly regular inter-seizure recordings show essentially similar changes after the injection of chlorpromazine. Differences between this group and the controls, which can be recognized without the help of a wave frequency analyser, lie in the more frequent occurrence of an obvious slow wave response, usually around 2 to $3 \mathrm{c}$./sec., a higher proportion of the lower frequencies $(4$ to $5 \mathrm{c}$. $/ \mathrm{sec}$.) in the theta range, and a more paroxysmal and bilaterally symmetrical appearance of these changes. There was one exception in a man of 36 who showed after 15 to 16 minutes bilateral runs of low-amplitude spikes in the posterior parietal regions.

Epileptic Patients in Group (a).-Table II shows in more detail significant abnormal features in this group seen before the injection of chlorpromazine either in the resting recording or after activation? by overbreathing or photic stimulation. Among

TABLE I

DISTRIBUTION OF SEX, AGE, NUMBER OF SEIZURES, AND MEDICATION

\begin{tabular}{|c|c|c|c|c|c|c|c|c|c|c|c|}
\hline \multirow[t]{3}{*}{ Group } & \multicolumn{2}{|c|}{$\begin{array}{c}1 \\
\text { Sex }\end{array}$} & \multirow[t]{3}{*}{$\stackrel{2}{\operatorname{Age}^{2}(y r .)}$} & $\begin{array}{l}\text { No. of }{ }^{3} \text { Seizures } \\
\text { per Patient }\end{array}$ & \multicolumn{2}{|c|}{$\stackrel{4}{\text { Medication }}$} & \multicolumn{5}{|c|}{ E.E.G. } \\
\hline & M. & F. & & & No. of & No. of Differ- & & $a$ & $b$ & $c$ & $d$ \\
\hline & & & & & & & & 节 & 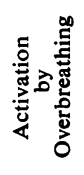 & 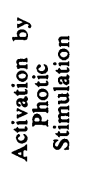 & 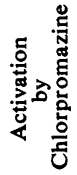 \\
\hline Epileptics $a$ & 14 & 6 & $\begin{array}{l}30 \mathrm{yr} . \\
(5-62)\end{array}$ & $\begin{array}{lr}<1 \text { per year } & 1 \\
<1 \text { per month } & 2 \\
>1 \text { per month } & 6 \\
>1 \text { per week } & 11\end{array}$ & $\begin{array}{l}0 \\
4 \\
7 \\
9\end{array}$ & $\begin{array}{l}0 \\
1 \\
2 \\
3\end{array}$ & $\begin{array}{l}\text { Delta } \\
\text { 3/sec. spike and wave } \\
\text { Spikes }\end{array}$ & 7 & $\begin{array}{l}6 \\
2 \\
5\end{array}$ & $\begin{array}{l}0 \\
1 \\
0\end{array}$ & $\begin{array}{c}6 \\
1 \\
12\end{array}$ \\
\hline Epileptics $b$ & 13 & 7 & $\begin{array}{l}31 \cdot 9 \mathrm{yr} . \\
(16-58)\end{array}$ & $\begin{array}{cc}<1 \text { per year } & 3 \\
<1 \text { per month } & 8 \\
>1 \text { per month } & 6 \\
>1 \text { per week } & 1 \\
\text { Not known } & 2\end{array}$ & $\begin{array}{l}2 \\
5 \\
7 \\
4 \\
2\end{array}$ & $\begin{array}{c}0 \\
1 \\
2 \\
3 \\
\text { Not known }\end{array}$ & $\begin{array}{l}\text { Delta } \\
\text { Spikes }\end{array}$ & $\begin{array}{l}0 \\
0\end{array}$ & $\begin{array}{l}2 \\
0\end{array}$ & $\begin{array}{l}1 \\
0\end{array}$ & $\begin{array}{l}6 \\
1\end{array}$ \\
\hline Control & 15 & 5 & $\begin{array}{l}37.6 \mathrm{yr} . \\
(18-65)\end{array}$ & 0 & $\begin{array}{l}15 \\
5\end{array}$ & $\begin{array}{l}0 \\
1\end{array}$ & $\begin{array}{l}\text { Delta } \\
\text { Spikes }\end{array}$ & $\begin{array}{l}0 \\
0\end{array}$ & $\begin{array}{l}1 \\
0\end{array}$ & $\begin{array}{l}0 \\
0\end{array}$ & $\begin{array}{l}3 \\
0\end{array}$ \\
\hline
\end{tabular}


TABLE II

RESULTS IN EPILEPTIC PATIENTS IN GROUP (a)

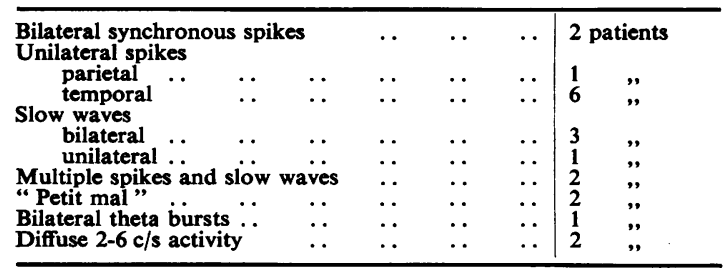

these patients with persistently abnormal interseizure recordings there were two in whom overbreathing caused definite abnormalities which were not seen after chlorpromazine. One man of 29 had a $3 / \mathrm{sec}$. generalized bilaterally symmetrical and synchronous spike-and-wave episode lasting about 25 seconds, the other, a man of 36 , showed a burst of three seconds' duration of spikes in the right posterior parietal region.

In the remaining 18 patients the following changes were seen after the injection:-(1) The abnormal features occur for longer periods. This was observed in $3 / \mathrm{sec}$. spike-and-wave episodes, focal temporo-parietal spike-and-slow-wave runs, and bilateral $2 \frac{1}{2} \mathrm{c}$./sec. anterior temporo-parietal bursts over prefrontal leucotomy lesions. (2) The abnormal features occur more often. This was seen in cases of unilateral temporal non-focal spikes and of temporal focal spikes, bilateral generalized multiplespike and slow-wave bursts and bilateral temporoparietal slow-wave bursts with spikes. (3) The amplitude of abnormal wave forms, in particular spikes, increases against a flatter background. (4) Asymmetries in respect of spikes and/or slow waves become more obvious, in part due to higher amplitude, flatter background, and greater frequency. (5) On many occasions abnormal activity is seen after tactile and acoustic stimulation, apparently related to fluctuations in the level of drowsiness. (6) As a rule several of these changes are seen in the same case.

No patient with a predominantly cortical epileptogenic focus causing Jacksonian attacks is included but cerebral trauma was known to exist in two cases, one with bilateral prefrontal leucotomy performed eight years earlier for conduct disorder accompanying epilepsy and one with epilepsy after a cerebral abscess after fracture of the skull in the frontal areas. The latter patient showed right-sided parietal spikes extending under chlorpromazine to the frontal and temporal areas on the same side. The clinical attacks in this case resembled psychomotor seizures.

Figs. 1-6 illustrate some of the points mentioned before. The upper part of each picture shows the
Fig. 1.-Recording No. 3450 (May 19, 1955). C. G., female, 35 years. Five to eight seizures per month.

Medication: Methoin $\quad . . \quad$.. 0.1 g.t.d.

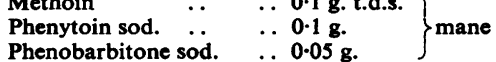

Thirteen minutes after injection, generalized multiple spikeand-slow-wave bursts.
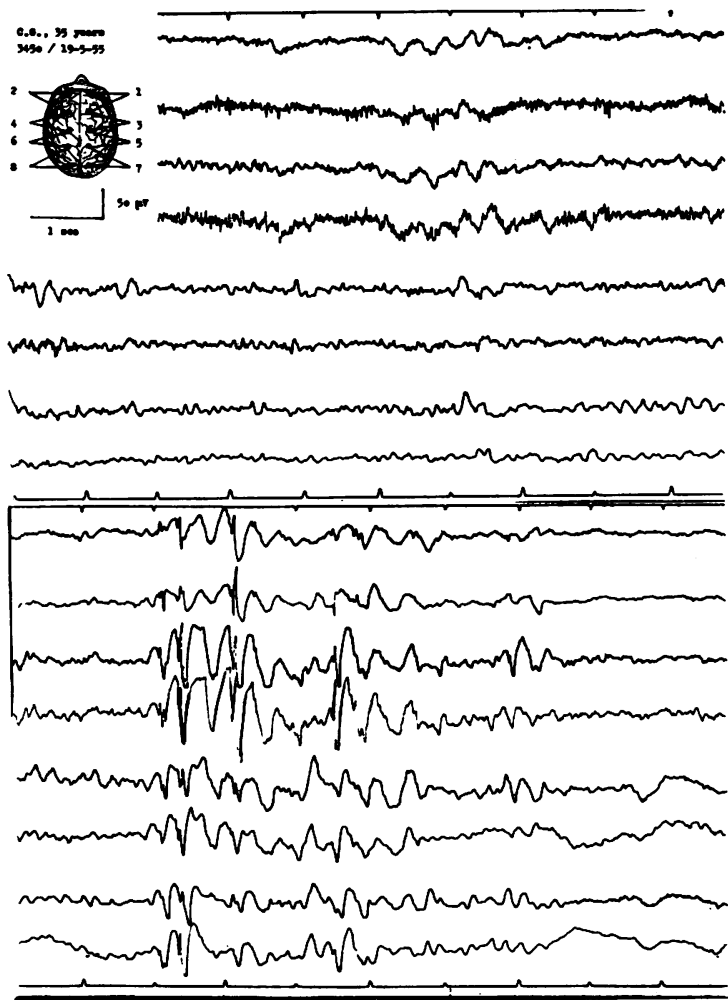

resting recording, the lower part the recording after chlorpromazine.

No convulsive seizures were observed during the investigation in any of the 60 patients. Alterations of consciousness occurred, as would be expected, in a child of 10 suffering from petit mal during the prolonged spike-and-wave discharges, and apparently in the patient C. G. (Fig. 1) during the multiple spike-and-slow wave bursts. Acoustic stimuli of a neutral character, e.g., tapping the desk with a pencil were most suitable to cause short arousal. In the E.E.G. the abnormal features characteristic of the particular case often became visible for a few seconds and this procedure was often successful when repeated, provided the patient was allowed to settle again in the drowsy state. Light touch to a limb came next as a suitable stimulus to cause short changes in the degree of drowsiness reflected in the E.E.G. Bright stroboscopic light flashes were less useful, probably due to the intensity of the 


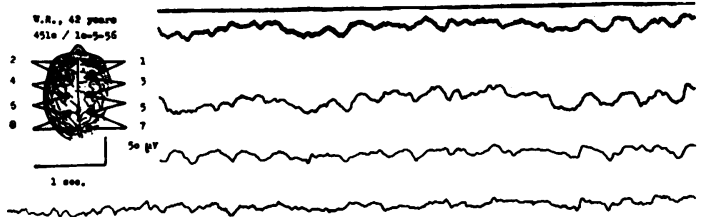

(1)

(2)

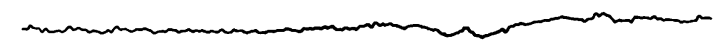

(1)

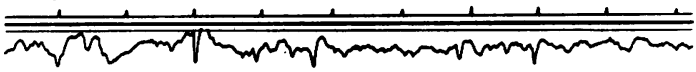

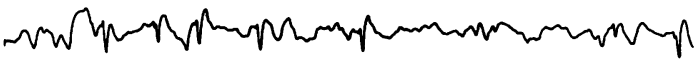
(1)

(n)

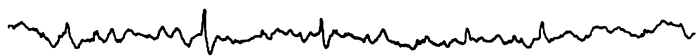

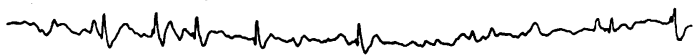

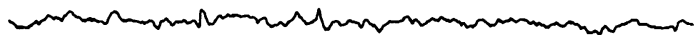

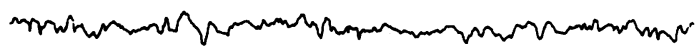

FIG. 2

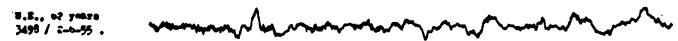

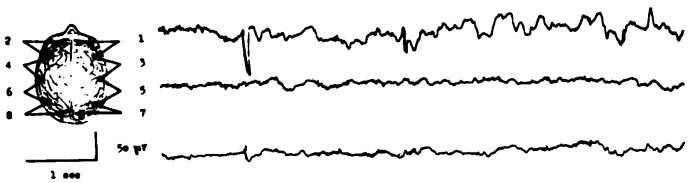
(2) (2)

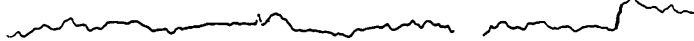

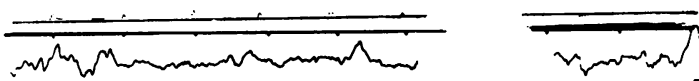
(ר) (1)

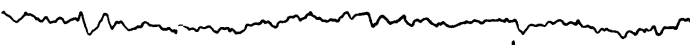

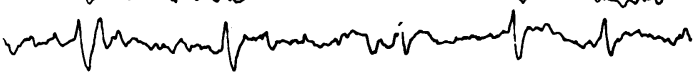
(n) $\mathrm{C}_{\mathrm{C}}$ FIG. ‘.

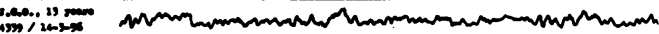

1,

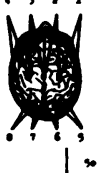

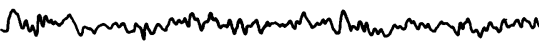

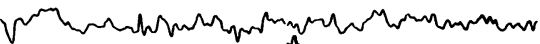

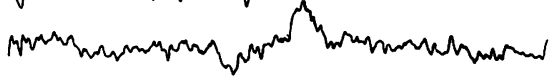
$2 \mathrm{cos}$

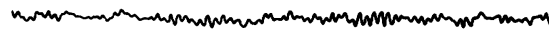

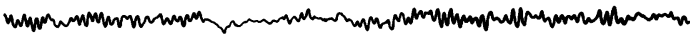

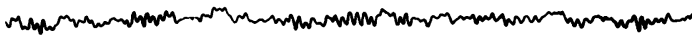

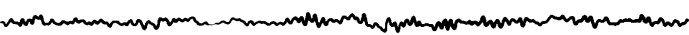

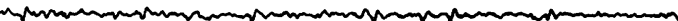

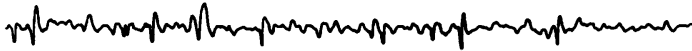

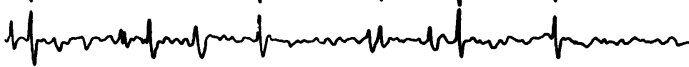

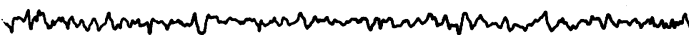

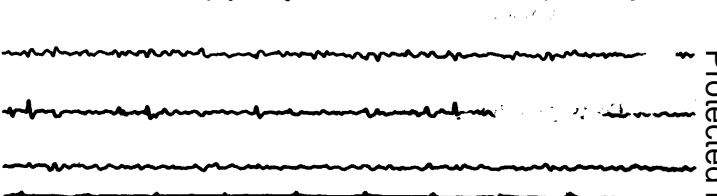

Fig. 3

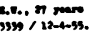

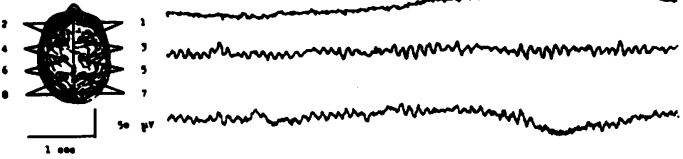
1 2.

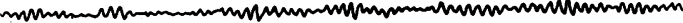

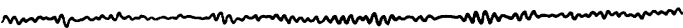
$\longrightarrow$ (1) 

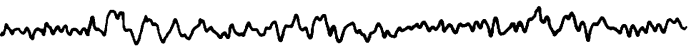

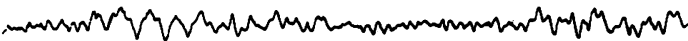

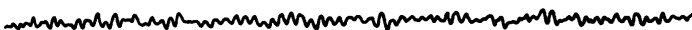

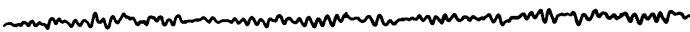

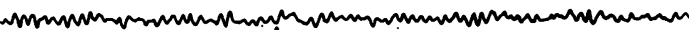

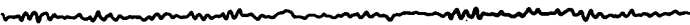

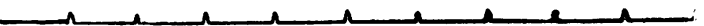

FIG. 5 
FIG. 2.-Recording No. 4510 (May 10, 1956). W. R., male, 42 years. Six to eight seizures per month.

Medication: Phenytoin sod. Phenobarbitone sod. Phenobarbitone sod.

$\left.\begin{array}{ll}\ldots & 0.1 \mathrm{~g} . \\ \ldots & 0.05 \mathrm{~g} .\end{array}\right\}$ t.d.s. .. 0.1 g. nocte

Thirty minutes after injection, sustained bilateral spike activity focal around a coronal anterior parietal plane.

FIG. 3.-Recording No. 4339 (March 14, 1956). J. G., male, 13 years. No seizures reported for three years. Medication: Phenytoin sod.
Phenobarbitone sod.

Forty-five minutes after injection, frequent bilateral synchronous single and grouped spikes, left of slightly higher amplitude than right, near the sagittal plane.

FIG. 4.-Recording No. 3498 (June 2, 1955). W. E., male, 62 years. Two to five seizures per month.

Medication: Phenytoin sod. Phenobarbitone sod.

$\left.\begin{array}{l}0.1 \mathrm{~g} . \\ 0.05 \mathrm{~g}\end{array}\right\}$ t.d.s.

Thirty-two minutes after injection, increase of number and amplitude of right-sided temporal spikes.

Fig. 5.-Recording No. 3339 (April 12, 1955). E. W., male, 27 years. About one seizure per month.

Medication: Penytoin sod.

$\begin{array}{ccc}\text { Phenobarbitone sod. } & \ldots & 0.05 \\ \text { Twenty-nine minutes after injection, biparietal synchronous }\end{array}$

$\left.\begin{array}{l}\text {. } 0.1 \text { g. } \\ \ldots 0.05 \text { g. }\end{array}\right\}$ t.d.s. 1 to $2 \mathrm{c}$./sec. slow waves near the location of prefrontal leucotomy cuts.

Fig. 6.-Recording No. 3974 (November 15, 1955). B. C., male, 18 years. $\mathbf{N}$ norous " dizzy bouts".

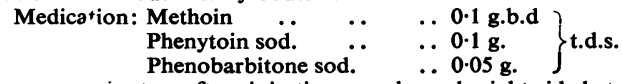

$\because c$ s after injection, prolonged right-sided temporo-occipital spike bursts starting one and a half seconds after a noise.

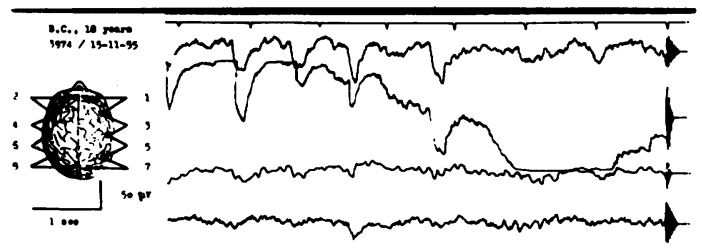

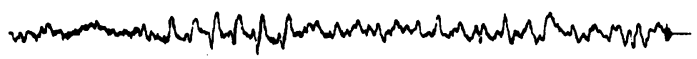

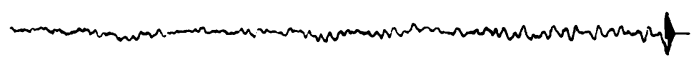

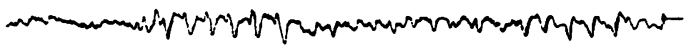

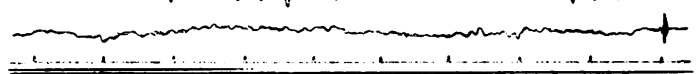

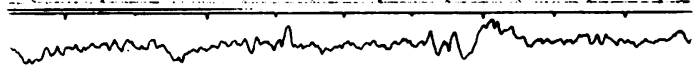

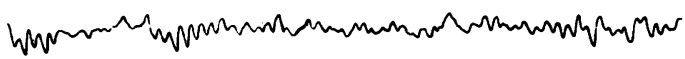

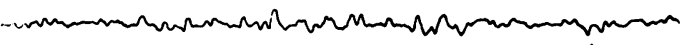

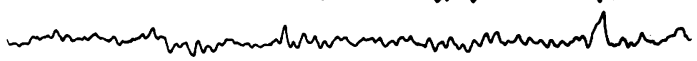

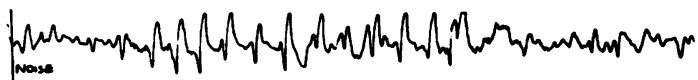

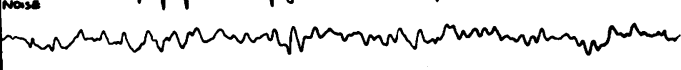

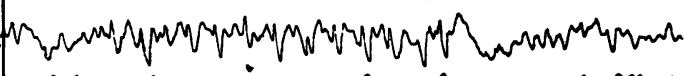

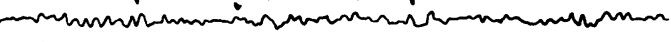

FIG. 6 illumination, and, when given in quick succession (between 3 and 16 flashes per second), because they prevented the patient from lapsing into the drowsy state. Changes during overbreathing after injection of chlorpromazine resembled those seen before injection but not those characteristic of the drowsy state. It appears, therefore, that the level of drowsiness and rapid short changes of this level bear some relation to the character of changes of the E.E.G. after injection.

Chlorpromazine caused a fall in the systolic blood pressure by about $20 \mathrm{~mm}$. $\mathrm{Hg}$ in the recumbent position, and patients were encouraged to lie on the examination couch for about 30 minutes to avoid postural hypotensive faints. In some cases the face was pale and the patients complained of sickness 15 to 20 minutes after the start of the injection. No relation was found between circulatory changes and changes in the E.E.G.

\section{Discussion}

The investigations show that intravenous chlorpromazine in doses of 0.3 to $0.5 \mathrm{mg}$. per $\mathrm{kg}$. body weight can cause increased paroxysmal and/or hypersynchronous activity in the E.E.G. of epileptic patients. The changes after the injection are essentially similar to those seen in this series of patients after activation by overbreathing and photic stimulation but they are often more obvious and of longer duration. They also resemble the changes observed in barbiturate-induced sleep and during insulin hypoglycaemia in the few patients where these methods had been used before chlorpromazine. The known abnormalities were enhanced but new abnormal features did not appear. The activation was more successful in unstable than in stable recordings, i.e., in patients with greater numbers of seizures more resistant to treatment. These findings are therefore similar to those described and illustrated by Bente and Itil (1954), Mayr and Lechner (1954), Szatmari (1956), and Turner et al. (1956). Lyberi and Last (1956) observed activation of the E.E.G. in their cises, which included a high proportion of patients with gross anatomical cerebral lesions, under very $\longleftarrow$ milar conditions. Investigations on animals using a : riteria the convulsive threshold for drugs and electric current are difficult to compare with each other and with clinical findings on account of the use of different animals and widely different dosage. The comparatively small doses used by Balestrieri (1955) and by Balestrieri and Franceschini (1956) in their investigations on rabbits (metrazol convulsions, 5 to $10 \mathrm{mg}$. chlorpromazine per $\mathrm{kg}$. body weight) $\mathrm{v}$.ry rarely raised the convulsive threshold, while Cuurvoisier et al. (1953) found protection against crramine, convulsions in mice 
with 80 to $100 \mathrm{mg}$. chlorpromazine per $\mathrm{kg}$. body weight. Amounts of similar magnitude would be unsuitable for clinical purposes. The clinical observations by Schlichther et al. (1956) indicate that relatively large amounts of chlorpromazine by mouth ( 400 to $600 \mathrm{mg}$. by mouth in one single dose) cause more frequent convulsions than lower doses but a definite relationship between dosage of the drug and frequency of seizures cannot be recognized from the data supplied in the papers.

The impression gained from most of the publications describing clinical observations is that in epileptic patients chlorpromazine can increase the number of seizures. Certain other groups of patients seen in mental hospitals and clinics may be rendered liable, too, to experience an increase of epileptiform convulsions under chlorpromazine. Many of these patients had received physical treatment for psychotic conditions (insulin coma treatment, leucotomy), or they suffered from intracranial tumours or other acquired or congenital anatomical cerebral lesions. In most of these patients seizures had been observed at some time or the other before chlorpromazine. In most of the papers which deal also with E.E.G. investigations increased paroxysmal and/or hypersynchronous electrical activity is reported. One can, therefore, conclude that chlorpromazine can increase an already existing proneness to (idiopathic) epileptic or (symptomatic) epileptiform seizures. This greater proneness can be accompanied by an increase of characteristic abnormal activity in the E.E.G. in the absence of clinical seizures. For this reason chlorpromazine can be considered a useful activating drug in clinical E.E.G. work, in particular when given by the intravenous route.

\section{Summary}

Chlorpromazine in doses of 0.3 to $0.5 \mathrm{mg} . / \mathrm{kg}$. body weight intravenously can increase abnormal phenomena in the E.E.G. of epileptic patients. In patients with unstable inter-seizure recordings activation of the E.E.G. is seen more often than in patients with rather regular inter-seizure recordings. The abnormal features observed after the drug are essentially similar to those seen in the resting recording or after activation by overbreathing or photic stimulation in the individual case. Convulsive seizures were not observed with the technique described here during or after the activation. These findings and a survey of the literature suggest that chlorpromazine should be useful as an activating drug in clinical E.E.G. work.

I wish to thank Dr. D. Macmillan, Physician Superintendent of Mapperley Hospital, for his permission to examine the patients in the hospital and for his interest in the investigation, and Mr. R. Darbyshire for his skilful technical assistance.

\section{REFERENCES}

Balestrieri, A. (1955). Arch. int. pharmacodyn., 103, 1.

, and Franceschini, V. (1956). Boll. Soc. ital. Biol. sper., 32, 197. Barsa, J. A., and Kline, N. S. (1956). A.M.A. Arch. Neurol. Psychiat., 76, 90 .

Bente, D, and Itil, T. (1954).Arzneimittel-Forschung, 4, 418.

Bonafede, V. A. (1955) A.M.A. Arch. Neurol. Psychiat. 74, 158. Courvoisier, S., Fournel, J., Ducrot, K., Kolsky, M., and Koetschet,

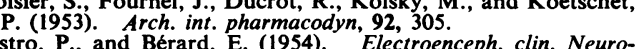
Castro, $P$., and $B$

Denber, H. C. B., and Bird, E. G. (1955). Amer. J. Psychiat., 112, 465.

Fabisch, W. (1955). Lancet, 1, 1277.

Kinross-Wright, V. (1955). Ann. N.Y. Acad. Sci., 61, 174.

Lomas, J. Boardman, R. H., and Markowe, M. (1955). Lancet, 1, 1144.

Lyberi, G., and Last, S. L. (1956). European Meeting E.E.G. Society, London, May, 1956. Abstract in Electroenceph. clin. Neurophysiol., 8, 711. (1956).

Mayr, F., and Lechner, H. (1954). Wien. klin. Wscher., 66, 903.

Moyer, J. H., Kinross-Wright, V., and Finney, R. M. (1955). A.M.A. Arch. intern. Med., 95, 202.

Munzinger, M. (1954). Schweiz. Arch. Neurol. Psychiat., 73, 357.

Robb, H. P. (1955). Lancet, 1, 1086.

Samad, I. A. (1955). Ibid., 1, 1327.

Schlichther, W., Bristow, M. E., Schultz, S., and Henderson, A. L. (1956). Canad. med. Ass. J., 74, 364

Schmid, M. (1954). Schweiz. Arch. Neurol. Psychiat., 73, 359.

Szatmari, A. (1956). Amer. J. Psychiat., 112, 788.

Terzian, H., and Ruberti, R. (1954). Riv. Neurol., 24, 686.

Turner, M., Bérard, E., Turner, N., and Franco, N. (1956). Electroenceph. clin. Neurophysiol., 8, 25.

Vaughan, G. F., Leiberman, D. M., and Cook, L. C. (1955). Lancet, 1,1083 .

Zanocco, G. (1955). Riv. Neurol., 25, 663. 